\title{
O PROCESSO DE ORGANIZAÇÃO SOCIAL DO GRUPO AGROECOLÓGICO HERANÇA VIVA DE CHAPECÓ-SC E SUAS ESTRATÉGIAS DE AÇÃO CONJUNTA
}

Luiz Paulo Klock Filho' Marcos Junior Marini² Wilson Itamar Godoy ${ }^{3}$

Resumo: O texto tem como objetivo, analisar o processo de organização social e ação conjunta realizado pelo Grupo Agroecológico Herança Viva do município de Chapecó/Santa Catarina. Para tal proposta foi adotada a opção metodológica da Pesquisa-ação. Para obter um melhor entendimento dos atores sociais e da organização social, foi utilizada a metodologia SWOT. No decorrer do trabalho, observa-se que o grupo aprimore suas dinâmicas de cooperação social/redes de relacionamento, e próprio papel político deste no que tange as políticas públicas que envolvam a agroecologia em Chapecó.

Palavras-chave: Organização Social. Agroecologia. Ação Conjunta. Atores Sociais. Cooperação Social.

\section{THE SOCIAL ORGANIZATION PROCESS AGROECOLOGICAL GROUP HERANÇA VIVA CHAPECÓ-SC AND ITS JOINT ACTION STRATEGIES}

Abstract: The text aims to analyze the process of social organization and joint action carried out by the Agroecological Herança Viva Group of the municipality of Chapecó / Santa Catarina. For this proposal was adopted the methodological option of Action Research. To obtain a better understanding of social actors and social organization, the SWOT methodology was used. In the course of the work, it is observed that the group improves its dynamics of social cooperation / relationship networks, and its own political role in what concerns the public policies that involve the agroecology in Chapecó.

Keywords: Social Organization. Agroecology. Joint Action. Social Actors. Social Cooperation.

\section{EL PROCESO DE ORGANIZACIÓN SOCIAL DEL GRUPO AGROECOLÓGICO HERANÇA VIVA DE CHAPECÓ-SC Y SUS ESTRATEGIAS DE ACCIÓN CONJUNTA}

Resumen: El texto tiene como objetivo, analizar el proceso de organización social y acción conjunta realizado por el Grupo Agroecológico Herança Viva del municipio de Chapecó / Santa Catarina. Para tal propuesta se adoptó la opción metodológica de la Investigación-acción. Para obtener un mejor entendimiento de los actores sociales y de la organización social, se utilizó la metodología SWOT. En el transcurso del trabajo, se observa que el grupo mejore sus dinámicas de cooperación social / redes

\footnotetext{
${ }^{1}$ Chapecó (SC), Brasil, luizpkfilho@gmail.com, https://orcid.org/0000-0002-2032-3013

2Universidade Tecnológica Federal do Paraná (UTFPR), Programa de Pós-Graduação em Desenvolvimento Regional (PPGDR), Pato Branco (PR), Brassil, marini@utfpr.edu.br, https://orcid.org/0000-0003-2539-0335

3Universidade Tecnológica Federal do Paraná (UTFPR), Programa de Pós-Graduação em Desenvolvimento Regional (PPGDR), Pato Branco (PR), Brasil, wigodoy@utfpr.edu.br, https://orcid.org/0000-0003-0152-6269
} 
de relación, y propio papel político de éste en lo que se refiere a las políticas públicas que involucran la agroecología en Chapecó.

Palabras clave: Organización Social. Agroecología. Acción Conjunta. Actores Sociales. Cooperación Social.

\section{Introdução}

A agricultura é um dos setores econômicos que sofreu forte influência do processo de modernização, principalmente relacionado às ferramentas tecnológicas utilizadas para o aumento da produção alimentar, desenvolvidas pelo modelo agroquímico.

Dentro dessa perspectiva, a agroecologia surge como uma alternativa para enfrentar uma sociedade baseada no reducionismo produtivista, sob o qual é estruturado o modelo vigente de produção agrícola, para um modelo de desenvolvimento mais integrativo, participativo e sustentável.

Para Altieri (2001), a busca por um desenvolvimento rural sustentável baseado em princípios da agroecologia está relacionada com a construção de sistemas locais, que levem em consideração os valores das pessoas, o seu conhecimento, sua forma de organização social e as tecnologias disponíveis em conjunto com o manejo ecológico de recursos naturais. Incorporados a uma ação social coletiva de caráter participativo, permita projetar a inclusão social em equilíbrio com a natureza.

Nesse sentido gerar o desenvolvimento de um grupo está associado à dinâmica do potencial territorial, à busca de alternativas de mercados locais e na sua organização social, em possibilitar iniciativas de reunião de pessoas com objetivos comuns, visando superar dificuldades e gerar benefícios. Isso permite a construção de condições mais amplas e melhores do que as que os indivíduos teriam isoladamente para a concretização de seus objetivos e de seus interesses.

A organização e a mobilização dos atores sociais são fundamentais para a dinâmica de sucesso para qualquer tipo de empreendimento que busca 0 desenvolvimento local. A mobilização social fortalece também a construção de planos de desenvolvimento que contemplam os potenciais e desejos da população local, respeitando a diversidade, cultura e valores daqueles que se engajam na melhoria e transformação dos seus territórios.

De acordo com Santos (2009):

[...] Um exemplo é a maneira como produtores rurais se reúnem para defender seus interesses, permitindo-lhes passar de um consumo puramente econômico, necessário às respectivas produções, a um 
consumo político localmente definido. [...] O território é arena da oposição entre o mercado - que singulariza - com as técnicas da produção, a organização da produção, "geografia da produção" e a sociedade civil - que generaliza - e desse modo envolve, sem distinção, todas as pessoas. (SANTOS, 2009, p.259).

À medida que grupos e atores sociais ampliam suas capacidades, podem mobilizar mais recursos e ativos e, por sua vez, encontram campo fértil para satisfazer suas demandas e interesses, os quais constituem relações de conflito e cooperação.

No atual panorama é importante perceber como grupos sociais, a partir de suas realidades, conseguem se relacionar com o grande capital e mantiver suas estruturas sociais de cooperação. Neste sentido, o presente trabalho tem como objetivo analisar o processo de organização social e ação conjunta realizado pelo Grupo Agroecológico Herança Viva do município de Chapecó/Santa Catarina.

Para cumprir tal proposta pode-se dividir o trabalho em três partes. $\mathrm{Na}$ primeira parte apresenta uma conceitualização dos eixos norteadores da pesquisa. Para isso, foi realizada uma descrição das concepções da agroecologia e do desenvolvimento endógeno, e suas relações para a construção do espaço rural sustentável.

A segunda parte apresenta a proposta metodológica utilizada. Sendo relatadas ações realizadas para analisar o grupo agroecológico, através da metodologia SWOT, além de identificar o universo de pesquisa e como ocorreu o levantamento de dados.

$\mathrm{Na}$ última parte é realizada a análise dos dados coletados através da pesquisa, ou seja, descrição das características do Grupo Herança Viva e suas estratégias de ação conjunta. Ao final, elaboram-se as considerações finais do estudo.

\section{AGROECOLOGIA: ESTRATÉGIAS PARA O FOMENTO DE AGROSSISTEMAS SUSTENTÁVEIS}

No espaço rural, através da agricultura industrial, representada pela Revolução Verde (a partir da segunda metade do século XX), na qual trazia no seu conjunto de alternativas um pacote de ações caracterizadas pela utilização de agroquímicos, mecanização da produção, a expansão de monocultivos, espécies melhoradas e padrões homogêneos de cultivo. Tal premissa trouxe problemas atrelados às condições ecológicas e das relações sociais nos territórios influenciados tais como aponta (ALTIERI 2012). 
Neste contexto a agroecologia propõe uma revisão de valores, sendo que a sua estrutura metodológica vai à direção de aumentar a participação dos agricultores na produção de conhecimentos. As demandas são direcionadas para compor as necessidades locais, respeitando os limites dos biomas e das estruturas sociais.

Para conquistar essas possibilidades a agroecologia tem como a base de interpretação dos agrossistemas, que se utiliza das dimensões ambiental, econômica e social para uma melhor compreensão dos territórios. Fundamentada na influência dos atores sociais envolvidos em suas comunidades rurais, com o fortalecimento das suas dinâmicas culturais e o poder decisório da produção sob seu controle. (FLORIANI \& FLORIANI, 2010)

A percepção por parte do produtor rural da sua realidade é de fundamental importância para a superação do modelo vigente, do abandono de práticas degradantes por outras mais sustentáveis. A transição agroecológica, envolve o protagonismo de atores sociais e com fortalecimento das suas dinâmicas locais. Envolvem contextos políticos de maior participação desses agricultores e suas organizações para as necessárias transformações ideológicas e sociopolíticas, como afirma Floriani \& Floriani (2010),

[...] na organização social e produtiva dos agricultores ecológicos familiares, em suma, a diversidade cultural das práticas de uso múltiplo dos recursos naturais - são responsáveis pela produção de emergências - reafirmando identidades [...] e enraizando uma racionalidade ambiental em territórios culturais para o desenvolvimento sustentável. (FLORIANI \& FLORIANI, 2010, p.20)

O papel das organizações e as relações sociais entre os atores, na produção, na socialização e o uso de conhecimentos e informações podem contribuir para o fortalecimento da cooperação, sendo capaz de gerar o desenvolvimento territorial rural.

\section{DESENVOLVIMENTO ENDÓGENO}

As iniciativas que colaboram com a formação de organizações sociais estimulam as participações da comunidade e podem se tornar ações que venham a fortalecer processos de desenvolvimento endógeno tornando os agricultores protagonistas da sua história.

Portanto, possibilitar iniciativas de reunião de pessoas com objetivos comuns, visando superar dificuldades e gerar benefícios, permite a construção de condições mais amplas e melhores que aquelas que os indivíduos teriam isoladamente para a concretização de seus objetivos e de seus interesses. Logo, a organização e a 
mobilização dos atores sociais são fundamentais para a dinâmica de sucesso para qualquer tipo de empreendimento que busca o desenvolvimento local (BANDEIRA, 1999).

As estruturas sociais que os envolvem geram laços de cooperação mais intensos e que podem ser visualizados nas interações das suas relações. Com este propósito, observa-se que:

\begin{abstract}
Nessas interações locais, desenvolve-se um conhecimento coletivo, o qual é diferenciado e desigualmente distribuído podendo ou não constituir importante fonte de dinamismo para aquele ambiente. Esse conhecimento coletivo não corresponde simplesmente à soma de conhecimentos de indivíduos e organizações; resulta das sinergias geradas a partir dos vários tipos de interação; e altera-se inclusive na sua interseção com a circulação globalizada de informação e conhecimento. (ALBAGLI e MACIEL, 2004, p.11)
\end{abstract}

É importante perceber as características que envolvam determinado território e os atores sociais envolvidos na construção cotidiana de suas estruturas. Mobilizar as estruturas endógenas, sendo interessante avaliar a formação do local, a dinâmica cultural, setores econômicos, níveis de integração e cooperação entre os vários indivíduos.

Marini et al. (2012) aponta que o desenvolvimento endógeno está muito além da base física, mas como os atores sociais estão articulados num determinado território. Portanto, o envolvimento social, a articulação dos potenciais de um dado território deve ser relevada, ou seja, é necessário conhecer a realidade de um espaço geográfico para caracterizar as suas territorialidades e motivações visando uma possível melhora do padrão de qualidade de vida.

\title{
PROCEDIMENTOS METODOLÓGICOS
}

Para tal análise foi utilizado como sujeitos da pesquisa, o grupo agroecológico Herança Viva, durante os anos de 2014 e 2015, que se localiza no município de Chapecó/SC.

A justificativa pela escolha do grupo está associada ao perfil caracterizado pelo seu vínculo com a agroecologia, da utilização de canais curtos de comercialização, principalmente a feira livre. Outra característica é forma de sua 
organização, vinculada a Rede $\mathrm{APACO}^{4}$ (Associação dos Pequenos Agricultores do Oeste Catarinense), que usa a certificação participativa ${ }^{5}$.

O grupo agroecológico Herança Viva tem sua formação no início dos anos 2000. Atualmente é constituído por 12 produtores rurais, vinculados à produção hortigranjeira. Para obter um melhor entendimento deste, foi utilizada a pesquisaação. O pesquisador, utilizando a observação participante, interfere no objeto de estudo de forma cooperativa com os participantes da ação para resolver um problema e contribuir para a base do conhecimento.

Conforme aborda Schimanski (2009):

Diferentemente de outros tipos de pesquisa, a metodologia da pesquisaação provê uma base teórico-metodológica que produz vida e voz a partir das relações estabelecidas pelos sujeitos envolvidos. Neste sentido, os participantes tornam-se sujeitos de uma relação que busca a articulação direta entre a teoria e a prática, pois os participantes são, ao mesmo tempo, "os teóricos" e os "práticos" da pesquisa. O caráter inusitado da pesquisaação provê, também, que os participantes sejam, ao mesmo tempo, "os sujeitos" e os "pesquisadores" da pesquisa em uma relação dialética que compreende o agir e o refletir deles em uma perspectiva transformadora da própria realidade social na qual estão inseridos. (SCHIMANSKI, 2009, p.93)

A obtenção dos dados aconteceu não só durante envolvimento nos processos organizacionais do grupo, mas também realizadas de maneira informal, almoços ou nas suas atividades recreativas.

No processo de análise foi utilizada como fonte documental secundária a ata de reuniões. Outro procedimento foi a aplicação de questionários com questões abertas e fechadas, caracterizando entrevistas estruturadas. Tal instrumento foi aplicado para 11 integrantes do grupo, já que o décimo segundo produtor rural voltou a ter uma maior participação das reuniões do grupo somente no mês de novembro de 2015. Tais informações foram utilizadas para obter os níveis de relacionamento e cooperação do grupo agroecológico Herança Viva.

\footnotetext{
${ }^{4} \mathrm{~A}$ Rede Ecovida surgiu no final dos anos 1990 devido às pressões mercadológicas pela regulamentação e especialmente da certificação de alimentos livres de agrotóxicos e outros componentes químicos de alta solubilidade (ROVER, 2011).

${ }^{5}$ Para Radomsky (2013) o processo de certificação participativa é compreendido em distintas fases: “ [...] A família que deseja "se converter" começa a compartilhar das reuniões do grupo local e permanece um ou dois anos no processo de transição. Neste período, deve seguir as normas da Ecovida. A própria família faz um mapa da propriedade e preenche um cadastro descrevendo-a com detalhes. Então, um agrônomo da prefeitura ou do serviço de extensão deve acompanhar a propriedade periodicamente fazendo visitas e depois elaborar um laudo. Logo após, o coordenador local encaminha à comissão de ética para esta realizar visita na propriedade. Feita a visita, a avaliação é encaminhada para a coordenação regional. Caso não haja problemas, a instância fornece o aval e a família pode obter o selo." (RADOMSKY, 2013, p.303)
} 
Durante o processo de análise do grupo foi realizada uma oficina para uma melhor compreensão do ambiente que envolve o grupo e suas perspectivas, 0 trabalho optou pela Metodologia de Diagnóstico - SWOT. No conjunto da ação foi utilizado o Diagnóstico Rápido Participativo - DRP, que consiste num conjunto de técnicas que permite que grupos/comunidades possam realizar seu próprio diagnóstico, e nesta ação possam ter um melhor reconhecimento da sua própria realidade. (VERDEJO, 2006, apud, MATTOS et al, 2011)

A atividade teve como objetivo identificar entre os integrantes as forças, fraquezas, oportunidades e ameaças no grupo (podendo perceber o âmbito externo e interno que os envolvem). E também a construção da missão, visão, valores e um plano de ação do grupo, sendo um momento importante de envolvimento dos participantes, pois, puderam entender relações que constituem sua organização e movimentos para a sua sustentação.

Tal procedimento foi realizado no período entre os dias 25 de novembro e 9 de dezembro de 2015, na feira central de Chapecó, o Grupo Agroecológico Herança Viva foi reunido para perceber suas particularidades. No contexto de oficina, os integrantes do grupo, foram submetidos a dinâmicas que os envolveram para refletir sobre o agrupamento social e a sua importância sobre a atividade que desenvolvem.

\section{CONTEXTUALIZAÇÃO DO CENÁRIO DO GRUPO AGROECOLÓGICO HERANÇA VIVA}

O grupo está localizado no município de Chapecó (Figura 1), que pertence à região oeste do Estado de Santa Catarina. Segundo o censo de 2010 (IBGE) o município conta com uma população residente de 183.530 pessoas, sendo que $8,4 \%$ reside na área rural, está é caracterizada como o centro dinâmico da economia da região, principalmente vinculado ao desenvolvimento das agroindústrias catarinenses. 
Figura 1: Localização do Município de Chapecó, SC

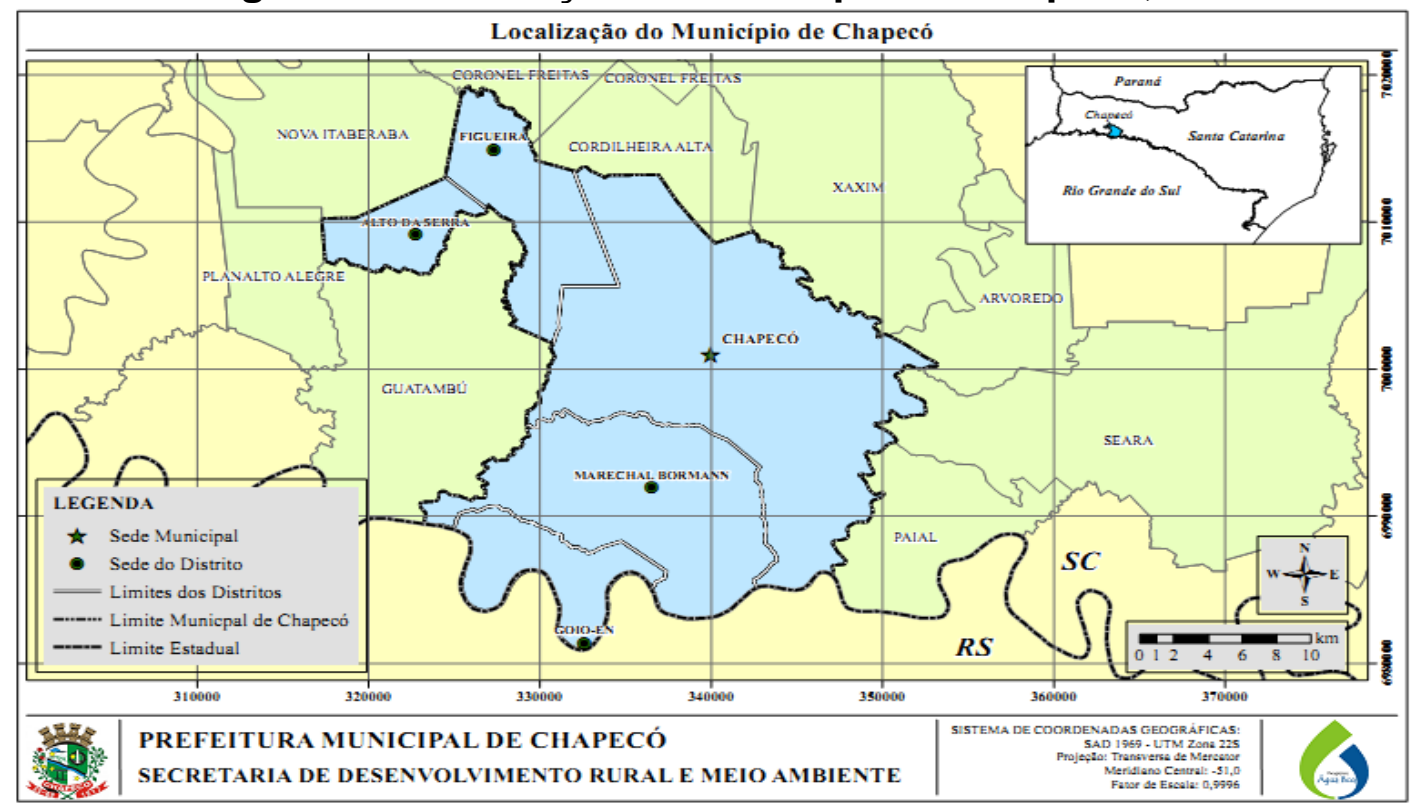

Fonte: Prefeitura Municipal de Chapecó

A origem do grupo está relacionado ao contexto político por que passava o município de Chapecó-SC à época. A cidade era governada por uma administração popular (final da década de 1990 e início dos anos 2000) a qual incentivou o fortalecimento das feiras-livres da cidade e, também, por incentivar as primeiras ações de produção orgânica no município ${ }^{6}$.

O grupo agroecológico Herança Viva é constituído por 12 produtores rurais (durante o período da pesquisa), vinculados à produção hortigranjeira, sendo formado por produtores que possuem certificação orgânica e que estão no processo de transição agroecológica.

As primeiras atividades do grupo, que estão registradas em ata de reunião (ano de 2002), relatam visitas do grupo à produtores rurais do município de Chapecó que já realizavam algumas práticas agroecológicas. As visitas eram acompanhadas por membros da prefeitura municipal, por professores de universidades da região e pesquisadores da Epagri (Empresa de Pesquisa Agropecuária e Extensão Rural de

\footnotetext{
${ }^{6}$ Radomsky et al (2014) coloca que mais detalhadamente sobre a particularidade do processo social em Chapecó, pode-se afirmar que, entre e 1998 e 1999, a prefeitura de Chapecó reforma as feiras livres, existentes desde o fim dos anos 1980. A ideia inicial, conduzida por agricultores interessados em transformar processos produtivos, mediadores, professores e técnicos do Estado, era de que todos os feirantes se convertessem para um sistema de produção agroecológica; no entanto, muitos não fizeram (alguns iniciaram e não conseguiram ou não quiseram completar a transição). O poder público, preocupado em não destituir o novo formato das feiras (que passaram a contar com novas estruturas e espaços na cidade) acabou aceitando agricultores convencionais e ecológicos, dando o nome de Feira de produtos coloniais e agroecológicos que ainda hoje acontece em dez pontos do município. (RADOWSKY, et al, 2014, p.55)
} 
Santa Catarina - órgão oficial de extensão rural e pesquisa agropecuária do Estado). No contexto de auxiliar possíveis dúvidas e mobilizar os agricultores na atividade de produção rural sustentável.

Diante desses fatores de formação do grupo, direcionados na conscientização dos membros sobre posturas adotadas na implantação do modelo agroecológico. As atividades começaram a ser vinculadas na divulgação da produção e de participar de eventos da cidade, para aumentar o reconhecimento da sociedade local sobre a atuação do grupo Herança Viva.

Outra etapa importante do grupo foi quando iniciou o processo de certificação das propriedades, comprovação que indica para os consumidores a origem dos produtos agroecológicos. Uma alternativa encontrada pelo grupo foi a adesão e mobilização da associação junto a Rede Ecovida, vinculada à APACO (Associação dos Pequenos Agricultores do Oeste Catarinense) ${ }^{7}$. Segundo Dorigon (2008, p. 209): "A participação na rede Apaco permite aos agricultores também terem acesso à rede de certificação ambiental participativa - Rede Ecovida, com vistas ao mercado de produtos orgânicos."

A certificação participativa consiste na informação das características locais da propriedade, onde a qualidade dos produtos é assegurada pela visita de agricultores, técnicos e consumidores que vão comprovar in loco a adequação do produtor, sendo este um processo de interação e controle social. A validação da garantia orgânica pelas Certificadoras e OPAC (Organismo Participativo de Avaliação de Conformidade) permite aos produtores certificados o uso dos Selos Ecovida e do SisOrg (MAPA - Ministério da Agricultura, Pecuária e Abastecimento) nos rótulos de seus produtos.

Com o desenrolar dos processos de certificação, o grupo começa a planejar novas formas de geração de renda junto às propriedades, incentivando as visitações de consumidores às propriedades dos integrantes. Outra ação foi investir também nos mercados institucionais, atrelados aos programas governamentais como o PAA (Programa de Aquisição de Alimentos) e o PNAE (Programa Nacional de Alimentação Escolar), fortalecendo os canais de comercialização curto.

\footnotetext{
${ }^{7}$ Segundo Dorigon (2008): A Apaco foi fundada em 1989 com o objetivo estimular e assessorar o desenvolvimento da agricultura de grupo no oeste de Santa Catarina. [...] Desde a sua criação a Apaco difundia entre seus associados o uso de tecnologias que reduzissem o custo de produção, preservassem recursos naturais e melhorassem as condições de trabalho, além de incentivar a cooperação agrícola e novas formas da organização da produção, buscando a autonomia dos agricultores em relação às grandes indústrias agroalimentares. (DORIGON, 2008, p. 200 e 201)
} 
Nota-se que a formação do Grupo Agroecológico Herança Viva esteve relacionada há um contexto vinculado ao fortalecimento de organizações sociais, como a Rede APACO. O fomento dado pela administração popular que governou o município de Chapecó de 1997 a 2004, a qual organizou as feiras-livres municipais, e o estímulo (através de reuniões) para que os agricultores começassem a produzir sem a utilização de agroquímicos e/ou a utilização de sementes modificadas geneticamente.

Porém, durante esse período e posteriormente, houve mudanças locais ocorridas nos âmbitos político, econômico e da própria conjuntura da dinâmica rural brasileira influenciada pelo fortalecimento do modelo da agroindustrialização convencional em grande escala. Tais premissas trouxeram dificuldades para a articulação do grupo, que acarretaram em problemas como:

- A fragilidade da assistência técnica, como a falta de profissionais para a orientação técnica mais efetiva para os agricultores destinados para a produção agroecológica;

- A ausência de planejamento da produção e da propriedade, os produtores tendo dificuldade em organizar e escrever no "caderninho de produção", que consiste em anotações que ajudam na elaboração do Plano de Manejo Orgânico da propriedade;

- $\quad$ A retração de mão de obra no campo, fatores como o êxodo rural e o envelhecimento dos trabalhadores rurais trazem consequências na produção devido à diminuição do efetivo;

- Nas feiras livres municipais há dificuldade para os consumidores visualizarem a diferença dos produtos agroecológicos dos produtos convencionais.

Todas as mudanças descritas fazem parte de um contexto que marca limitações no crescimento do grupo, porém, também associado ao próprio contexto organizacional do Grupo Agroecológico Herança Viva e de seus processos de cooperação que enfraqueceram ao longo do tempo.

\section{PROCESSOS E ESTRATÉGIAS DE AÇÕES CONJUNTAS NO GRUPO AGROECOLÓGICO HERANÇA VIVA \\ A construção de espaços em qu \\ e os indivíduos de um determinado local moldam suas relações sociais e} assim trocam experiências, expectativas e possibilidades para que juntos possam conduzir ações de benefício coletivo são premissas que condicionam a formação 
das organizações sociais. É necessário reconhecer como esses envolvimentos contribuem para a identidade do grupo e para o seu próprio sucesso. Como aborda Bauman (2005)

\begin{abstract}
Afinal de contas, a essência da identidade - a resposta à pergunta "Quem sou eu?" e, mais importante ainda, a permanente credibilidade da resposta que lhe possa ser dada, qualquer que seja - não pode ser constituída senão por referência aos vínculos que conectam o eu a outras pessoas e ao pressuposto de que tais vínculos são fidedignos e gozam de estabilidade com o passar de tempo. Precisamos de relacionamentos aos quais possamos referir-nos no intuito de definirmos a nós mesmos. Mas em função dos comprometimentos de longo prazo que eles sabidamente inspiram ou inadvertidamente geram, os relacionamentos podem ser, num ambiente líquido moderno, carregados de perigos. (BAUMAN, 2005, p. 74 e 75)
\end{abstract}

O processo da globalização trouxe uma expansão do capitalismo que interfere tanto nas relações de produção como também na própria organização dos indivíduos em seus territórios (Godoy, 2005). Bauman (2005) colabora ao dizer que:

A globalização atingiu agora um ponto em que não há volta. Todos nós dependemos uns dos outros, e a única escolha que temos é entre garantir mutuamente a vulnerabilidade de todos e garantir mutuamente a nossa segurança comum. Curto e grosso: ou nadamos juntos ou afundamos. Creio que pela primeira vez na história da humanidade o autointeresse e os princípios éticos de respeito e atenção mútuos de todos os seres humanos apontam na mesma direção e exigem a mesma estratégia. (BAUMAN, 2005, p. 95)

Acomodação e diminuição do compromisso por parte dos integrantes do Grupo Agroecológico Herança Viva, que não aprimoraram seus processos de organização, representado pela ausência da descrição de reuniões nas atas apresentadas nos períodos entre 2000 a 2001 e 2008 a 2010. Demonstrando certo afastamento do relato de suas ações, como pode ser visto no gráfico 1.

\title{
Gráfico 1: Reuniões do Grupo Agroecológico Herança Viva registradas
} em ata.

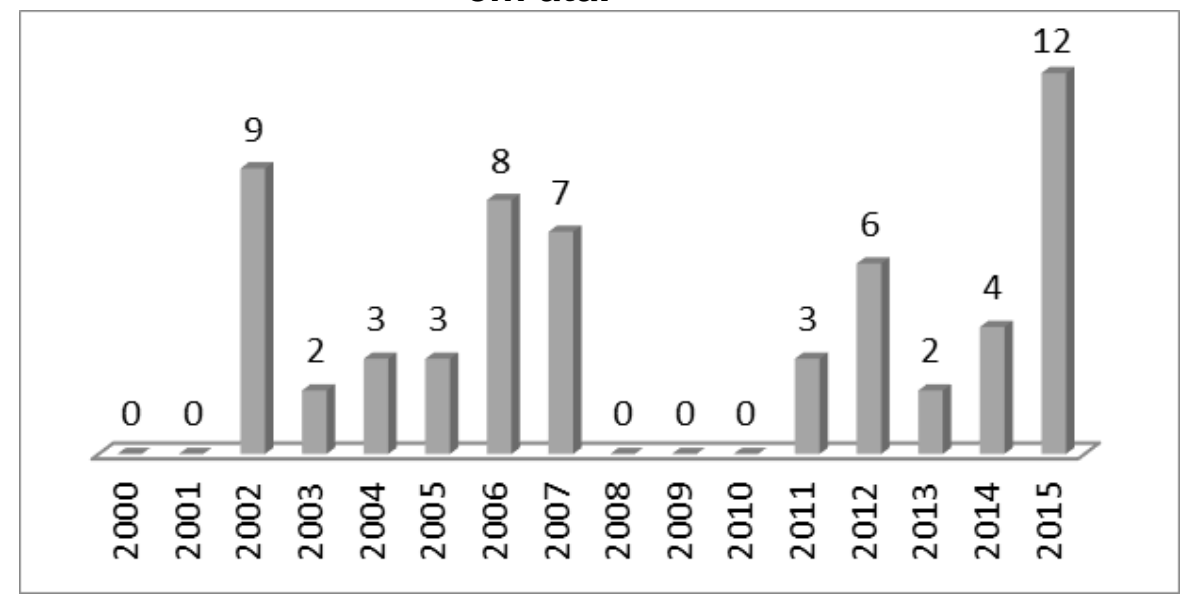

Fonte: Elaborado a partir dos dados da pesquisa dos autores 
A falta do registro na ata de reunião mostra a perda das informações contidas naquele encontro do grupo, ou seja, uma parte da história que não vai ser mais recuperada, dificultado assim a sua própria evolução. Segundo os produtores nesses períodos em que não houve a ata oficial, foram realizadas visitas nas propriedades dos membros e a situação do grupo agroecológico, mas sem haver uma preocupação em registrar os acontecimentos através da formalidade de um documento.

O atual momento é considerado pelos seus membros, como uma etapa de reconstrução do grupo. Dos integrantes que fazem parte do Herança Viva, 50\% aderiu ao grupo entre os anos de 2013 a 2015. A entrada de novos membros pode ser notada como fator de agregação, pois com as novas presenças houve um registro crescente no número de atas de reuniões, o ano de 2015 teve o maior número de reuniões na existência da associação (gráfico 1).

Outro dado do atual contexto do grupo está na participação dos membros e familiares nos encontros. Entre os anos de 2014 (sendo realizadas 4 reuniões e com a média de 8,75 participantes) e 2015 (sendo realizadas 12 reuniões e com a média de 15,66 participantes), corresponde um maior envolvimento, demonstrado no gráfico 2.

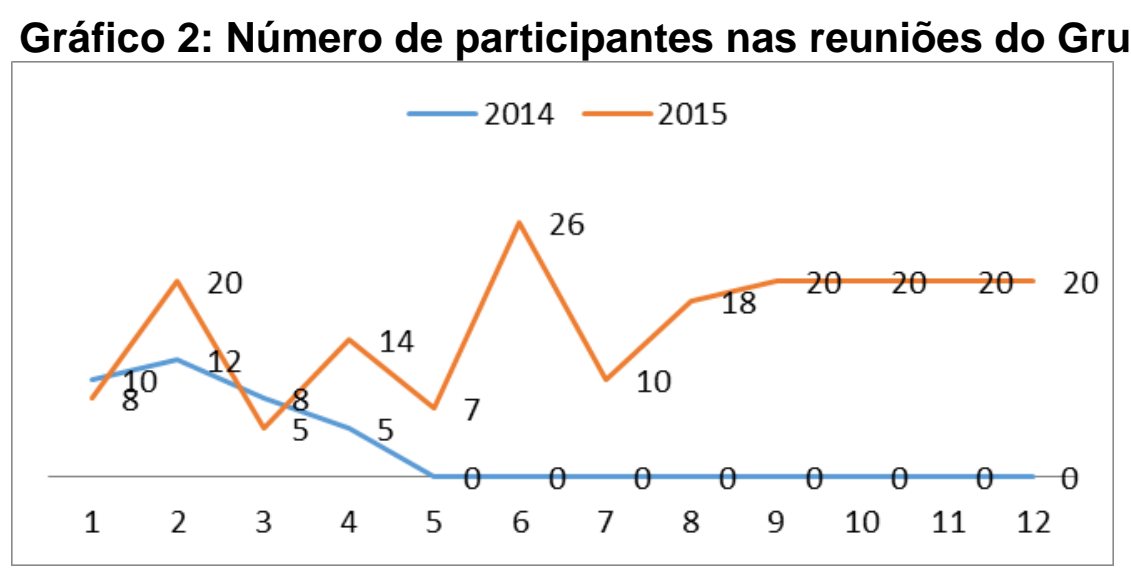

Fonte: Elaborado a partir dos dados da pesquisa dos autores.

$\mathrm{Na}$ construção de um grupo, a participação significa uma postura ativa de envolvimento e corresponsabilidade dos diversos atores sociais, na tomada de decisão sobre as formas de enfrentamento das externalidades. Constrói-se, dessa forma, um projeto mais ampliado e real. Além disso, é a participação que dá legitimidade política e social a ação.

Segundo Zani (2012):

Supõe-se que essas relações de confiança, de colaboração e de identidade compartilhadas pelos atores locais evoluam gradativamente para espaços mais estáveis e autênticos de consulta, articulação e deliberação, valendo- 
se de níveis mais elevados de articulações horizontais e verticais, que consolidem os avanços alcançados e canalizem as demandas sociais. (ZANI, 2012, p.197)

Dentro dessa premissa um dos primeiros itens que pode ser observado é o nível de confiança que os membros do Herança Viva tem com a dinâmica organizativa e decisória existente. Para alcançar essa resposta, os produtores foram questionados qual seria a nota para esse requisito, sendo 5 para o mais alto nível e 1 para o mais baixo. Obteve-se então uma média de 3,45.

Tal nota, quando observada dentro da escala de Likert, pode ser considerada uma avaliação entre regular e boa. Este dado fica mais evidente quando $64 \%$ dos integrantes reconhecem que o Herança Viva é um espaço de socialização de mecanismo de trocas.

A socialização segundo os produtores ocorre de diferentes maneiras, mas principalmente na ampliação das informações e acesso de conhecimento da agroecologia. As formas de como essa ação ocorrem podem ser através: das visitas das propriedades realizadas pelo grupo a cada dois meses (caracterizado por um momento confraternização e por trocas de experiências), na realização de cursos qualificação, troca, fornecimento, utilização e tratamento de produtos. Também no acesso de novos canais de comercialização e produtos indicados pelos membros do grupo entre si, e na cooperação entre os agricultores através dos mutirões nas propriedades (auxílio de mão de obra).

As atividades ocorrem através das reuniões que geram uma sintonia no grupo, ou seja, como uma estratégia de articulação importante para a execução de suas atividades agrícolas e de comercialização.

A outra informação importante é que $36 \%$ dos entrevistados não reconhecem a socialização, mesmo que seja um universo menor. Isso pode ser justificado, pois, alguns membros apontam desconfiança em decisões tomadas pelo grupo, na questão se todos os componentes respeitam normativas definidas nas reuniões e também que muitas ações desenvolvidas pelo Herança Viva descritas acima tiveram sua atuação mais intensificada no ano de 2015.

Como a atual fase do grupo é de reestruturação de seus processos organizativos, tal resposta vem ao encontro de alguns procedimentos adotados no decorrer da sua existência. Em observação realizada nas reuniões, pode-se notar que as normas estabelecidas e redigidas em atas de reuniões, não estão sendo cumpridas na sua totalidade:

- Não houve registro de reuniões na ata; 
- Falta de controle das obrigações dos integrantes (presença);

- O processo de comunicação apresenta dificuldades (aviso sobre reuniões);

- Não há divisão de responsabilidades (atividades do grupo ficam a encargo do coordenador e do secretário);

- Novos membros desconhecem a origem do grupo;

- A dificuldade de alguns componentes da associação na produção agroecológica gera dúvidas entre os integrantes sobre a qualidade dos produtos.

Para alcançar qualquer objetivo dentro de uma organização social, é importante que os membros tenham a percepção de aspectos que estão relacionados na dinâmica de funcionamento da estrutura que os envolvem. $O$ processo dialógico possibilita a construção dessa percepção, como se a cada debate, a cada atividade, a cada projeto, uma nova "lente" se apresentasse diante dos olhos e possibilitasse a identificação dos diferentes contextos, assim como a melhor compreensão do papel dos integrantes na melhoria do grupo.

Dentro desse contexto o Grupo Agroecológico Herança Viva vive um momento de transição de suas ações, passando assim a analisar seus procedimentos e buscar novas possibilidades de fortalecimento. Essa premissa é apontada na ata do dia 19 de julho de 2014:

\begin{abstract}
[...] foi levantado questões quanto as dificuldades que a Apaco está tendo em acompanhar o grupo, dificuldades de reunir o grupo pra debater e resolver os problemas do grupo, a preocupação quanto ao produto que está sendo comercializado pra feira enquanto agroecológico, onde em análises realizadas identificou contaminação em alguns itens, levantou-se questões referente a comercialização dos produtos, e a forma com que são tratados no sistema agroecológico [...] a importância da organização e articulação do grupo e a importância de integrar novas famílias, ter cronograma de reuniões estipulado, a confiança entre os membros do grupo, definir responsabilidade, fica encaminhado que cada membro vai fazer uma análise sobre o que quer pra sua propriedade e pro grupo e construir um planejamento estratégico do grupo levantando todos os problemas existentes e definido metas a serem superadas.[...]
\end{abstract}

No mês de agosto de 2014, o Grupo Herança Viva realizou uma reunião no Mercado Público Municipal de Chapecó, com o apoio da CooperFamiliar (Cooperativa Alternativa da Agricultura Familiar). Esse encontro teve a finalidade de discutir as questões abordadas no trecho acima mencionado. Mas as discussões trabalhadas naquele momento não foram retomadas nos meses à frente, tornando mais uma ação sem algo de concreto.

Em março de 2015 com a eleição para a nova coordenação do grupo e com as atividades desenvolvidas pela pesquisa, começa um novo ciclo de mudanças e de retomadas de assuntos para a organização do grupo. As reuniões regulares 
mensais pelo grupo foi um dos momentos de integração importante. Através desses encontros pôde-se encontrar soluções de problemas, como a própria troca de informações entre os produtores, que conseguem a partir dessa periodicidade manter o direcionamento, o foco e controle de suas atividades.

A dinâmica que envolve essa atividade é feita da seguinte forma: uma reunião na Feira Central de Chapecó tendo como objetivo assuntos gerais e, no mês seguinte, na propriedade de um dos membros do Herança Viva, que tem um caráter de socialização a partir da observação dos outros integrantes das práticas realizadas pelo produtor no seu ordenamento agrícola.

Dentro da reunião realizada na propriedade, os integrantes foram provocados pelo pesquisador, no sentido de intensificar suas atividades em conjunto, não ficando apenas reunidos durante a venda dos seus produtos nas feiras livres e durante as reuniões, mas que aumentassem a cooperação entre os componentes.

Nesse sentido surge a possibilidade de realizar um mutirão, onde reúnem-se para suprir alguma dificuldade que os produtores rurais do grupo enfrentam relacionado a falta de mão de obra. A atividade nesta direção foi realizada no mês de junho de 2015, na colheita das sementes do feijão-guandu, sendo a primeira vez que tal evento foi realizado pelo grupo na sua história, depois as sementes ficaram à disposição dos outros integrantes.

A prática não foi repetida durante o restante do ano devido às dificuldades de organização para retomá-la. Porém, ela foi bem-sucedida e o grupo pretende colocar tal prática como prioridade para o ano de 2016.

Nas ações em conjunto desenvolvidas pelo grupo durante o ano de 2015, também foi pensada e realizada a diversificação de produtos oferecidos pelos produtores aos seus consumidores. Sendo realizada uma oficina sobre a produção de cogumelos Shitake no mês de setembro.

A capacitação foi realizada através de um "Dia de Campo", durante um dia inteiro os produtores e um técnico trocaram informações sobre o produto e as suas tendências de mercado. A escolha por tal cultivo busca outra possibilidade para a diversificação da produção, como também uma prática que alia o conhecimento tradicional aproveitando os recursos locais, gerando renda e aliada com a preservação ambiental.

As ações em conjunto do grupo não foram baseadas somente em atividades, mas também na adoção e cobrança de procedimentos. Um deles é a exigência da anotação no "caderninho de produção", descrevendo a origem dos insumos 
utilizados no plantio, e o maior controle dos produtores da sua produção e, como tal, essa operação é fundamental para obtenção da certificação dos produtos.

Os agricultores do Herança Viva tem dificuldades e até mesmo esqueciam de fazer as anotações. Nas reuniões foi definido que o "caderninho de produção" deveria ser trazido nas reuniões para tirar dúvidas do preenchimento e nos encontros nas propriedades o produtor visitado deveria mostrar suas anotações e relatar sua experiência para os demais integrantes.

No entanto o Herança Viva tem limitações na organização de suas atividades e bem como na própria estruturação de seus regimentos, levando muitas vezes ao enfraquecimento do engajamento de seus membros. Para criar uma maior sensibilização do grupo frente a essa demanda, no mês de dezembro de 2015, foi realizada em dois momentos uma oficina de SWOT e DRP.

Para identificar as características que envolviam o grupo, foi realizado em conjunto as ferramentas de diagnóstico, de forma a construir a proposição de estratégias para a solução dos problemas encontrados, e o próprio fortalecimento dos produtores e da sua organização.

A importância do planejamento segundo Andrade (2012):

\begin{abstract}
Para que a organização possa vir a se articular rumo aos objetivos pretendidos, é necessário que esta considerem tanto as oportunidades e as ameaças ambientais como os seus pontos fortes e pontos fracos internos. Desse modo, dependendo do contexto externo e interno encontrado, a empresa deverá adotar um posicionamento estratégico com a finalidade de orientar a futura definição dos objetivos e das estratégias de ação necessárias. (ANDRADE, 2012, p. 77)
\end{abstract}

Para realizar tal atividade o grupo reuniu-se na Feira Central de Chapecó. $\mathrm{Na}$ primeira parte da oficina foram trazidos elementos sobre o cenário agrícola atual que Herança Viva está inserido. Posteriormente foram apresentados dados referentes à interação social dos membros da associação. Nesse momento foram resgatadas as origens do Herança, a valorização da história da entidade pelos seus integrantes com objetivo de ratificar os seus valores formadores.

No terceiro momento os integrantes analisaram o ambiente interno (forças e fraquezas) e externo (oportunidades e ameaças) que envolvem a associação. Cada um desses componentes, em maior ou menor grau, influencia direcionamentos da organização, exigindo que seus componentes estejam sempre atentos às novas exigências e influências que estarão no seu cotidiano. No momento da oficina o grupo identificou os seguintes pontos que são apresentados no quadro 1. 
Quadro 1: Ambiente interno e externo do Grupo Agroecológico Herança Viva

\begin{tabular}{|l|l|l|l|}
\hline \multicolumn{3}{|c|}{ Ambiente Intemo } & \multicolumn{2}{c|}{ Ambiente Extemo } \\
\hline Pontos Fortes & Pontos Fracos & \multicolumn{1}{|c|}{ Oportunidades } & \multicolumn{1}{c|}{ Ameaças } \\
\hline -Projeto de & -Participação; & -Novos Mercados; & -Denúncias; \\
Vida; & -Demora nas & -Mais tecnologia & -Questionamentos \\
-Persistência; & atuações; & para a produção; & dos produtos e \\
-Confiança; & -Divulgação do & -Aumento da & produtores, \\
-Troca de & Grupo; & conscientização dos & -Falta de mão-de- \\
Ideias; & -Conscientização; & consumidores; & obra nas \\
-História do & -Explicação dos & -Crescimento & propriedades; \\
grupo; & produtos; & populacional da & -Sucessão; \\
-Espaços de & -Desorganização; & cidade; & -Manter a \\
Venda; & -Desânimo; & -Divulgação na & regularidade da \\
-Qualidade dos & -Falta de & mídia; & produção; \\
produtos; & Conhecimento; & -Expansão do & -Grandes empresas \\
-Conhecimento. & -Prática de cultivo; & grupo; & do setor de \\
-Diversidade de & -Falta desconfiança; & -Trazer mais & alimentos \\
produtos; & -Comunicação; & familias produtoras & \\
-Agricultura & -Trabalhar o & para o grupo; & \\
Familiar; & associativismo; & -Possibilidades de & \\
-Participação & -Falta de Assistência & parceria com outros & \\
nas reuniões; & -Falta de mão-de- & grupos e & \\
-Produção & obra & instituições & \\
Orgânica & & & \\
\hline
\end{tabular}

Fonte: Elaborado a partir dos dados da pesquisa dos autores.

Diante dos contextos interno e externo, identificados, foi definido um plano de ação para que possa construir alternativas para a superação das dificuldades e o aprimoramento das qualidades que foram identificadas pelos participantes do grupo, sendo definida a quarta etapa da oficina.

O plano de ação é uma ferramenta para acompanhamento de atividades que foram selecionadas pelo grupo por um determinado período visando suprir determinados pontos que são considerados impedimentos para o crescimento da associação. Porém, antes de pensar alguma ação a ser realizada, é indicado reconhecer qual são os objetivos do grupo. Para isso é foi estabelecido os princípios organizativos da organização para então estabelecer um caminho a ser seguido.

No quadro 2, serão demonstrados a Missão, Visão, Lema e os Valores do Grupo Herança Viva, que foram definidos pelos seus integrantes. 


\section{Quadro 2: Princípios Organizativos do grupo}

\begin{tabular}{|c|c|}
\hline & $\begin{array}{l}\text { Missão } \\
\text { Produzir e formecer alimentos agroecológicos de qualidade } \\
\text { da Agricultura Familiar. }\end{array}$ \\
\hline & $\begin{array}{l}\text { Visão } \\
\text { Ser um grupo de referência nacional em alimentos } \\
\text { agroecológicos da Agricultura Familiar. }\end{array}$ \\
\hline & $\begin{array}{l}\text { Lema } \\
\text { Implantar na propriedade uma cultura de administração, } \\
\text { planejamento, voltado à valorização das necessidades e } \\
\text { desejos das pessoas. }\end{array}$ \\
\hline & $\begin{aligned} \text { Valores } & \\
\text { - } & \text { Respeito a pessoa; } \\
\text { - } & \text { Qualidade de alimentos; } \\
\text { - } & \text { Persistêncção; } \\
\text { - } & \text { Dedicação; } \\
\text { - } & \text { Empatia; } \\
& \text { Sustentabilidade Socioambiental }\end{aligned}$ \\
\hline
\end{tabular}

Fonte: Elaborado a partir dos dados da pesquisa dos autores.

A realização dos princípios organizativos contribuiu para que o grupo, juntamente com a análise do seu ambiente externo e interno, definisse os principais pontos que iriam constituir o plano de ação para 2016, sendo composto por 5 temáticas:

- Aprimoramento do registro da ata de reuniões;

- Maior controle e detalhamento dos procedimentos;

- Comunicação externa e interna mais eficiente e efetiva;

- Maior divisão de responsabilidades entre os membros;

- Acompanhamento da produção.

Para cumprir as temáticas os integrantes foram divididos em 5 subgrupos: Coordenação, Regimento Interno, Divulgação, Comunicação Interna e Assistência Técnica. Neste sentido, o grupo ficou com a incumbência de nas próximas reuniões encaminharem suas ações. Tais premissas reforçam as perspectivas de ações conjuntas e o envolvimento dos integrantes no desenvolvimento do grupo.

\section{Considerações Finais}

A sociedade atual baseada nos valores de um modelo econômico que prioriza a competição e o individualismo, dentro da lógica do consumismo desenfreado que degrada os recursos naturais. Tal cenário parece não ter espaço para outras possibilidades que possam repensar os padrões que a humanidade adotou ao longo 
do tempo. Todo esse conjunto trouxe uma grande incerteza à sustentabilidade da nossa civilização.

A crise socioambiental baseada na desigualdade gerada pelo modelo dominante força a sociedade a repensar toda uma estrutura. Sendo necessária uma nova visão da realidade, que possa rever pensamentos, percepções e valores, trazendo para a discussão uma postura dinâmica, aberta e dialógica, contribuindo para uma visão crítica das questões e de suas possíveis soluções.

Dentro desse contexto as discussões sobre organizações sociais ganham importância, pois nestes espaços as formas de relacionamento entre os membros e outras instituições, a construção de regras de conduta, a configuração na construção dos seus objetivos de trabalho e a própria maneira dos integrantes exercerem sua cidadania são pontos que podem, a partir da coletividade, repensar o papel destes indivíduos dentro da sociedade, como na construção de um outro mundo possível.

Frente a todo este cenário foi possível conhecer a gênese do grupo e entender como ação política da Prefeitura Municipal de Chapecó no final da década de 1990 e início dos anos 2000 foi determinante para a sua formação. Tal ação foi decisiva para o processo inicial e para atração dos primeiros produtores, porém, com a mudança da gestão pública no governo municipal, houve um enfraquecimento, demonstrando a forte dependência de agentes externos que existe, sendo necessária uma maior autonomia dos seus integrantes na sua condução. Esse aspecto vem influenciado na forma do engajamento dos seus membros.

Nesse sentido, a realização da oficina de SWOT e DRP colaborou para que os agricultores do Herança Viva, pudessem rever práticas do grupo e, em conjunto, pensar soluções para o seu fortalecimento, ou seja, trazendo todos para discutirem, avaliarem e tomar iniciativas que busquem a coesão de suas ações,que poderá tornar-se uma ferramenta permanente dentro do grupo, para um processo continuo de avaliação e definição de metas da organização.

Diante do exposto, observa-se que o Grupo Herança Viva demonstra que passa por diferentes níveis de transição, sendo necessário analisar suas dinâmicas de cooperação social. Como ampliação dos contatos com outros grupos e próprio papel político da associação no que tange as políticas públicas que envolvam a agroecologia em Chapecó. Neste sentido, necessita-se que o avanço nas diferentes dimensões poderá fortalecê-lo.

A grande articulação passa necessariamente em trazer os membros do grupo para pensar contextos que o enriqueçam, assegurando a participação de todos, para 
proporcionar um ambiente de transformação e tornar o processo de mudança significativo para as pessoas desde o começo.

\section{REFERÊNCIAS}

ALBAGLI, Sarita; MACIEL, Maria Lúcia. Informação e Conhecimento na Inovação e no Desenvolvimento Local. Ci. Inf., Brasília: v.33, n.3, pg. 9-16, 2004.

ALTIERI, Miguel. Agroecologia. A dinâmica produtiva da agricultura sustentável. $5^{\underline{a}}$ edição Porto Alegre: Editora da UFRGS, 2001. p. 23-65.

ALTIERI, Miguel. Agroecologia: Bases científicas para uma agricultura sustentável. 3eeição. São Paulo, Rio de Janeiro: Expressão Popular, AS-PTA, 2012.

ANDRADE, Arnaldo Rosa de. Planejamento estratégico: formulação, implementação e controle. São Paulo: Atlas, 2012.

BANDEIRA, Pedro. Participação, Articulação de Atores Sociais e Desenvolvimento Regional. Brasilia- DF: IPEA- Instituto de Pesquisa Econômica Aplicada, fevereiro de 1999.

BAUMAN, Zygmunt. Identidade: entrevista a Benedetto Vecchi. Tradução Carlos Alberto Medeiros. Rio de Janeiro: Jorge Zahar Ed., 2005.

DORIGON, Clóvis. Mercados de produtos Coloniais da Região Oeste de Santa Catarina: em Construção. 2008. 437 f. Tese (Doutorado em Engenharia de Produção) Universidade Federal do Rio de Janeiro, Rio de Janeiro, 2008.

FLORIANI, Nicolas; FLORIANI, Dimas. Saber ambiental complexo: aportes cognitivos ao pensamento agroecológico.Rev. Bras. de Agroecologia, Porto Alegre, 5( 1): 3- 23 (2010).

GODOY, Wilson Itamar. As Feiras-Livres de Pelotas, RS: Estudos sobre a Dimensão Socioeconômica de um Sistema Local de Comercialização. Pelotas; UFPel, 2005.

MARINI, Marcos Junior et al. Avaliação da Contribuição de arranjos Produtivos Locais para o Desenvolvimento Local. Biblio 3W - Revista Bibliográfica de Geografía y Ciencias Sociales. Universidade de Barcelona. Vol. XVII, n. 996, 15 de octubre de 2012.

MATTOS, C.A.C.de; SILVEIRA PINTO, W. de; CARDOSO, A.G; SILVA,R.L.da \& BRIENZA JUNIOR,S. Estratégias de planejamento a partir do diagnóstico rápido participativo e da análise swot: um estudo na comunidade de São Bento, Salinopólis - PA. Sociedade e Desenvolvimento Rural online - v.5, n. 2 - Dez - 2011.

RADOMSKY, Guilherme. F.W. Certificações, sistemas participativos de garantia e agricultura ecológica: aspectos da relação entre agricultores e consumidores. In: NIEDERLE, Paulo André, ALMEIDA, Luciano de, VEZZANI, Fabiane Machado (orgs). Agroecologia: Práticas, Mercados e Políticas para uma nova agricultura. Curitiba/PR: Kairós, 2013. p.297 a 326.

RADOWSKI, Guilherme F. W.; CARVALHO, Cyntia X de.; BASTOS, Valério V.; MALAGODI, Edgard. Inovações técnico-produtivas, dispositivos coletivos e desenvolvimento rural: a agroecologia no Oeste de Santa Catarina e no Agreste da Paraíba.In: SCHNEIDER, Sérgio, MENEZES, Marilda, SILVA, Adenor Gomes da, BEZERRA, Islandia (orgs.).Sementes e 
Brotos da transição: inovação, poder e desenvolvimento em áreas rurais do Brasil. Porto Alegre/RS: Editora da UFRGS, 2014. p. 49 a 69.

ROVER, Oscar José. Obstáculos e exigências para a governança regional. Revista Brasileira de Gestão e Desenvolvimento Regional. G\&DR, v. 7, n. 1, p. 130-152, janabr/2011, Taubaté/SP.

SANTOS, Milton. A Natureza do Espaço: Técnica e Tempo, Razão e Emoção. $4^{a}$ edição, 5 ${ }^{\text {a }}$ reimpressão. São Paulo: Universidade de São Paulo, 2009.

SCHIMANSKI, Édina. Pesquisa-ação como instrumento de pesquisa social críticoemancipatória. In: Jussara A. Bourguignon. (Org.). Pesquisa Social - reflexões teóricas e metodológicas. Ponta Grossa/PR: Toda Palavra, 2009.

ZANI, Felipe Barbosa. O Programa de Desenvolvimento Sustentável dos Territórios Rurais pela ótica da cidadania deliberativa. In: TENÓRIO, Fernando Guilherme (orgs). Cidadania e desenvolvimento local: critérios e análise. Rio de Janeiro: FGV, 2012. p.181 a 206.

\section{NOTAS DE AUTOR}

\section{CONTRIBUIÇÃO DE AUTORIA}

Luiz Paulo Klock Filho- Concepção. Coleta de dados, Análise de dados, Elaboração do manuscrito, revisão e aprovação da versão final do trabalho

Marcos Júnior Marini - Concepção. Coleta de dados, Análise de dados, Elaboração do manuscrito, revisão e aprovação da versão final do trabalho.

Wilson Itamar Godoy - Concepção e elaboração do manuscrito. Coleta de dados Participação ativa da discussão dos resultados; Revisão e aprovação da versão final do trabalho.

\section{FINANCIAMENTO}

Bolsa de Estudo do PPGDR/CAPES.

CONSENTIMENTO DE USO DE IMAGEM

Não se aplica.

APROVAÇÃO DE COMITÊ DE ÉTICA EM PESQUISA

Não se aplica.

\section{CONFLITO DE INTERESSES}

Não se aplica.

\section{LICENÇA DE USO}

Este artigo está licenciado sob a Licença CreativeCommons CC-BY. Com essa licença você pode compartilhar, adaptar, criar para qualquer fim, desde que atribua a autoria da obra.

\section{HISTÓRICO}

Recebido em: 21-12-2018

Aprovado em: 05-03-2019 